\title{
METODOLOGIA ATIVA NA GRADUAÇÃO MÉDICA: A VISÃO DOS DISCENTES DA SAÚDE SEGUNDO A LITERATURA
}

\section{ACTIVE METHODOLOGY IN MEDICAL GRADUATION: THE VISION OF THE HEALTH STUDENTS ACCORDING TO THE LITERATURE}

\author{
Pâmela Alegranci ${ }^{1}$ \\ Gleici Filipetto Segato² \\ Alexandra Secreti Prevedello ${ }^{3}$
}

RESUMO: A formação dos profissionais médicos exige gradativamente, transformações e mudanças em sua metodologia, com a finalidade de oferecer ao Sistema Único de Saúde, profissionais éticos, políticos, autônomos, humanistas, sensíveis e capazes de compreender o ser humano como um todo, que age de forma preventiva, humanizada, e não só curativa, como priorizavam os métodos tradicionais. As metodologias ativas surgiram com o intuito de formar estes profissionais. Neste processo de aprendizagem, que coloca o aluno no centro da sua busca por conhecimento, a memorização repetitiva dá lugar a memorização compreensiva, com consequente aprendizado significativo. Neste artigo se analisará a atuação da metodologia ativa na graduação médica, com enfoque no Problem Based Learnig $(\mathrm{PBL})$, e se refletirá a respeito do ponto de vista dos discentes em relação às novas metodologias, assim como seu impacto na formação profissional.

PALAVRAS-CHAVE: metodologias ativas de ensino- aprendizagem, Problem Based Learnig (PBL), educação médica.

ABSTRACT: The training of medical professionals gradually requires changes in its methodology, in order to offer to the Unique Health System, an ethical, political, independent, humanist, sensitive professional and able to understand the human being as a whole, which acts preventively, humanized and not only curative, as prioritized traditional methods. The active methods have emerged in order to form these professionals. In this learning process, which places the student at

\footnotetext{
${ }^{1}$ Doutora em Biociências e Biotecnologia aplicadas à Farmácia Docente da Faculdade de Medicina da UFMT, Sinop-MT, Brasil. palegranci@gmail.com

${ }^{2}$ Especialista em Medicina Intensiva Pediátrica. Docente da Faculdade de Medicina da UFMT, Sinop-MT, Brasil. gleicifi@hotmail.com

${ }^{3}$ Especialista em Sexologia. Docente da Faculdade de Medicina da UFMT, Sinop-MT, Brasil.alexandraprevedello@gmail.com (Epub Ahead of Print 08 out.,2017)
}

Rev. Fac. Educ. (Univ. do Estado de Mato Grosso), Vol. 28, Ano 15, № 2 p. 99-112, jul./dez. 2017 (Epub Ahead of Print 8. out., 2017) 
the center of your quest for knowledge, repetitive memorization gives way to understanding memory, with consequent significant learning. In this article will be analyze the performance of active methodology in medical schools, focusing on Problem Based Learnig (PBL), and will reflect about the point of view of students in relation to new methodologies, as well as its impact on vocational training.

KEYWORDS:active teaching-learning methodologies, Problem Based Learnig (PBL), medical education.

\section{Introdução}

No desempenho das atividades profissionais de saúde há falhas, burocracia, falta de plena implantação dos princípios do Sistema Único de Saúde (SUS) e baixa capacidade dos profissionais que adentram suas portas para resolver os problemas de saúde da população. No Ensino, há a premência em formar o profissional cidadão, reflexivo e crítico, inserido na coletividade que a população necessita. Na Gestão, no Estado, há a necessidade de fortalecer, por meio de políticas e medidas institucionais, a formação dos profissionais de saúde que prestarão e prestam serviço à população (GOMES; REGO, 2011).

Diante destes pilares que formam o quadrilátero: população, serviço, ensino e gestão, existe um almejado desejo de formação de um novo profissional para a área da saúde, profissionais estes, que aliem competência técnica, ética e humanística.

É sabedoria antiga de todos que o ensino superior em saúde, sobretudo o ensino médico, sofre duras críticas em diversos aspectos, despertando o reconhecimento internacional da necessidade de mudança.

Demonstra-se que a formação profissional desvinculada da prática em serviço influi diretamente na qualidade do atendimento à população. Depara-se cada vez mais com profissionais médicos que desconhecem ou desvalorizam tanto a relação médico-paciente, quanto o vínculo e o cuidado ao sujeito que necessita da sua prática. É, portanto, importante que haja uma reorientação da formação, abandonando-se o modelo hegemônico e tradicional, e partindo em busca de metodologias que formem o profissional excelente.

Historicamente, a formação dos profissionais de saúde tem sido pautada pelo uso de metodologias conservadoras, sob forte influência do mecanismo de inspiração cartesiana-newtoniana, fragmentado e reducionista (CAPRA, 2006).De acordo com Mitre (2008) "essa fragmentação do saber 
manifestou-se no aguçamento das subdivisões da universidade em centros e departamentos e dos cursos em períodos ou séries e em disciplinas estanques". Assim, o processo ensino- aprendizagem tem se restringido à reprodução dos conteúdos, no qual o docente assume um papel de transmissor de informação, ao passo que, cabe ao aluno a retenção, memorização e repetição dos mesmos, tornando-se um mero expectador, sem estimular sua crítica e reflexão.

No modelo hegemônico, fundamentado pelo modelo de Flexner em 1910, que vinha ao encontro da necessidade de resolver inúmeros problemas relacionados à formação médica na época; a formação tem por base um currículo tradicional, que não estimula adequadamente o desenvolvimento de autonomia, capacidade de análise, julgamento e avaliação, bem como raciocínio crítico, investigativo e criativo (PAGLIOSA; ROS, 2008).

A ênfase na sólida formação em ciências básicas nos primeiros anos do curso, a organização minuciosa da assistência médica em cada especialidade, a valorização do ensino centrado no ambiente hospitalar enfocando a atenção curativa, individualizada e unicausal da doençaproduziram um ensino dissociado do serviço e das reais necessidades do sistema de saúde vigente (MARSIGLIA, 1995; MITRE, 2006).

Não se pode negar que as práticas em saúde vêm incorporando um grande e admirável desenvolvimento técnico e cientifico, porém, torna-se cada vez mais evidente que a crise da legitimação desta prática traz consigo a perda da qualidade do atendimento médico. De que vale este profissional obter habilidades conquistadas pela tecnociência, sem ser capaz de desenvolver habilidades éticas e humanísticas a fim de garantir a saúde do seu paciente?

Portanto, as abordagens pedagógicas progressivas do ensino- aprendizagem vem sendo construídas e implicam formar profissionais como sujeitos sociais com competências éticas, políticas e técnicas e dotados de conhecimento, raciocínio, crítica, responsabilidade e sensibilidade, capacitando-os para intervirem em contextos de incertezas e complexidades (MITRE, 2008).

De acordo com Mitre (2008), "as metodologias ativas estão alicerçadas em um princípio teórico significativo: a autonomia, com o objetivo de gerar um discente capaz de auto gerenciar seu processo de formação".

Ter sempre diante dos olhos - e dentro do coração - o respeito à autonomia parece ser o melhor modo para a compreensão, por parte do binômio docente/discente, do processo de produção, expressão e apreensão do conhecimento, dentro de uma perspectiva de transformação da realidade (MITRE, 2008).

Considerando, portanto, que as mudanças metodológicas tem sido

Rev. Fac. Educ. (Univ. do Estado de Mato Grosso), Vol. 28, Ano 15, № 2 p. 99-112, jul./dez. 2017 (Epub Ahead of Print 8. out., 2017) 
amplamente defendidas por inúmeros especialistas no Brasil como fator determinante na melhoria da qualidade do ensino médico; nesta publicação, através de dados de revisão bibliográfica, será descrito inicialmente as características dos métodos conhecidos com "metodologias ativas de ensino- aprendizagem", enfocando o Problem Based Learnig (PBL) e em seguida abordado os resultados desta revisão bibliográfica explicitando a visão dos discentes diante da metodologia ativa.

\section{Entendendo a metodologia ativa de ensino- aprendizagem}

Tendo como premissa básica que a saúde é um direito de todos e um dever do Estado, a Constituição da República assegura o exercício dos direitos sociais e individuais, a liberdade, a segurança, o bem-estar, o desenvolvimento, a igualdade e a justiça como valores supremos (GOMES, REGO, 2011).

O Sistema Único de Saúde (SUS), em seu artigo 198, tem como diretrizes a descentralização, com direção única em cada esfera do governo; o atendimento integral, com prioridade para as atividades preventivas, sem prejuízo dos serviços assistenciais; e a participação da comunidade. Neste contexto, durante o período de formação do profissional médico, deve-se fomentar tais princípios já mencionados com a finalidade de garantir um atendimento integral e excelente ao cidadão.

A Lei de Diretrizes e Bases da Educação Nacional/LDB surge no cenário da educação superior definindo, entre suas finalidades, o estímulo ao conhecimento dos problemas do mundo atual (nacional e regional) e a prestação de serviço especializado à população, estabelecendo com ela uma relação de reciprocidade (BRASIL, 1996). Tais prerrogativas foram reafirmadas pelas Diretrizes Curriculares Nacionais, em 2001, para a maioria dos cursos da área de saúde, determinando a importância do atendimento às demandas sociais com destaque para o SUS. Estas diretrizes curriculares priorizam também, a formação de um profissional com uma visão ampliada da clínica e um senso de responsabilidade social, que não signifique apenas atender o paciente, mas principalmente, tomá-lo como cidadão; visando atingir, ao final do curso, a meta de formação de um profissional cidadão, crítico e reflexivo (BRASIL, 2001).

Ainda em 2001, em busca de reorientar os produtos da escola médica a fim de reforçar as mudanças no modelo de atenção à saúde e fortalecer a atenção básica, é lançado o Programa de Incentivo a Mudanças Curriculares nos Cursos de Medicina (Promed). Este apresenta a necessidade de mudanças 
em diversos pontos da formação: orientação teórica, abordagem pedagógica e cenários de prática. Para isto, explicita o estabelecimento de protocolos de cooperação entre os gestores do SUS e as escolas médicas; a incorporação da noção integralizada do processo saúde-doença e da promoção da saúde com ênfase na atenção básica; a ampliação dos cenários e da duração da prática educacional na rede de serviços básicos de saúde; a adoção de metodologias pedagógicas ativas e centradas no estudante (BRASIL, 2002).

Em 2005, os ministérios da Saúde e Educação lançam o Programa de Reorientação da Formação Profissional (Pró-Saúde), com o objetivo de reorientar a formação profissional, visando a integração ensino-serviço, assegurando uma abordagem integral com ênfase na atenção básica (BRASIL, 2007).

No auge da mudança, surgem as metodologias ativas de ensinoaprendizagem como panaceia da formação do estudante de Medicina, em busca do perfil das Diretrizes Curriculares Nacionais (BRASIL, 2001).

A metodologia ativa de ensino pode ser entendida como uma estratégia centrada no aluno, deslocando seu papel anterior de receptor passivo, assumindo a posição principal na responsabilidade do seu aprendizado. Um aprendizado que engloba a auto iniciativa, as dimensões afetivas e intelectuais, através do exercício da curiosidade, da emoção e da responsabilidade, instigando sua capacidade crítica de observar e investigar o objeto, para com isso confrontar, questionar, conhecer ou reconhecer e atuar sobre ele.

A metodologia ativa coloca o estudante ao lado do professor que deverá assumir o papel de orientador e mediador do processo educativo. Dessa forma, o estudante deve ser ativo, questionador e curioso, com iniciativa, ético e responsável. Já o professor/tutor precisa ter vontade e capacidade de permitir ao estudante participar ativamente do seu processo de aprendizagem.

De acordo com Coll (2000), existem duas condições para a construção da aprendizagem significativa: a existência de um conteúdo potencialmente significativo e a adoção de uma atitude favorável para a aprendizagem, ou seja, a postura própria do discente que permite estabelecer associações entre os elementos novos e aqueles já presentes na sua estrutura cognitiva.

Por conta destas características, a metodologia ativa vem sendo muito utilizada no contexto de mudanças na formação profissional da área de saúde, sobretudo no ensino médico, já que, com caráter dinâmico, pontua que o professor ou educador deve ser reconstrutor do conhecimento sob o ponto de vista não só da ciência e tecnologia, mas também da humanização na educação; permitindo uma aprendizagem significativa, e não simplesmente a memorização mecânica isolada, e a real apreensão dos conceitos fundamentais

Rev. Fac. Educ. (Univ. do Estado de Mato Grosso), Vol. 28, Ano 15, № 2 p. 99-112, jul./dez. 2017 (Epub Ahead of Print 8. out., 2017) 
ao estudo da Medicina.

As metodologias mais utilizadas nesta transformação no Brasil, são a problematização e a aprendizagem baseada em problemas (ABP) ou Problem Based Learnig (PBL), a qual aprofundaremos nossos entendimentos a seguir.

\section{Problem based learnig (PBL)}

A metodologia PBL caracterizou-se como uma filosofia curricular e pode ser considerada uma solução de melhoria da qualidade do processo ensino- aprendizagem, funcionando como eixo do aprendizado teórico do currículo médico, integrando as disciplinas, a teoria e a prática.

O PBL foi concebido no Canadá nos anos 1960, na Universidade de McMaster, espalhando-se pelo mundo, inclusive no Brasil. Tem como principais fundamentos: a aprendizagem por descoberta, a aprendizagem significativa, a indissociabilidade entre a teoria e a prática, o currículo integrado, a valorização da autonomia do estudante, o trabalho em pequeno grupo e a avaliação formativa, proporcionando o desenvolvimento de um profissional cooperativo, respeitoso, com capacidade de escutar o outro, habilitado a trabalhar em equipe, autônomo, crítico e reflexivo (WOOD, 2003). Tem como eixos centrais de funcionamento o espaço de trabalho em grupo tutorial e a busca ativa individual pelo estudante (NTYONGA-PONO, 2006). Estes, em pequenos grupos trabalham na resolução de situações- problemas que servem de mote para a busca de conteúdo, conceito e habilidades cognitivas.

Distribuídos em pequenos grupos nas atividades de sessões de tutoria, os estudantes se defrontam com situações ou problemas elaborados por docentes, com o objetivo de desafiar a aprendizagem em busca da compreensão e explicação do problema.

Segundo Komatsu, Zanolli e Lima (1998), cada problema deve refletir o cotidiano da prática profissional, antecipá-lo como acontecimento aos estudantes que se preparam para a atuação, permitindo uma reflexão contextualizada sobre aquela temática, a seleção de recursos educacionais, a busca de informações, a avaliação crítica e a aplicação.

Estudos sobre o PBL realizados por vários pesquisadores no mundo mostram a comparação do PBL com o ensino tradicional. Almeida (2001), destaca que, na década de 1990, o PBL e o ensino orientado à comunidade são vistos como abordagens mais integradoras que as tradicionais. Entretanto, são insuficientes e sujeitas a distorções, porque o PBL não pode se restringir 
às manifestações superficiais de fenômenos isolados, mas deve aprofundar as explicações dos problemas de saúde, discutindo-os em sua integralidade, o que requer a incorporação e o fortalecimento das ciências básicas e sociais.

A metodologia ativa visa formar profissionais com características peculiares ao exercício de uma medicina competente tecnicamente, mas aliada sempre ao compromisso ético e à concepção ampliada de saúde, onde cuidar é valorizar, criar vínculo e se responsabilizar pela integralidade das ações. Mas, diante disso, qual é a visão do estudante, já que sua formação prévia à graduação se deu sempre de modo tradicional? É o ponto que discutiremos a seguir.

\section{A visão do discente diante da metodologia ativa}

Há uma escassez de dados fundamentados sobre o impacto da metodologia ativa sobre os graduandos de Medicina no Brasil, o que dificulta esta análise. Sabe-se, no entanto, da necessidade de avaliar este marcador, que influencia diretamente no profissional que se quer formar ao fim do curso.

As literaturas analisadas, revelam, aos olhos dos discentes, pontos negativos e positivos do uso de metodologia ativa durante a graduação. Em estudo de caso com abordagem qualitativa, realizado na Faculdade de Medicina de Marília em 2002, com discentes do primeiro semestre, ao falarem sobre o PBL, alguns estudantes expressaram emoções negativas que revelaram um sentimento de solidão, por se considerarem autodidatas. Estes estudantes mostraram, com tais sentimentos, a não compreensão dos papéis dos docentes neste currículo e método de ensino- aprendizagem, o que ainda poderia revelar a necessidade de capacitação dos docentes nos novos papéis (MORAES; MANZINI, 2006).

Já em relação a estratégia de trabalhar em pequenos grupos de estudantes, os discentes a valorizaram para desenvolver novas atitudesde trabalho em grupo, acrescentando, à aprendizagem de conhecimentos, mudanças de atitudes e valores compartilhados em grupos colaborativos (MORAES; MANZINI, 2006).

Sobre a mudança do currículo, da metodologia tradicional, que eles vivenciavam anteriormente, para a metodologia ativa, a reação dos estudantes foi incialmente "de choque". E, segundo os estudantes, "o choque" inicial continuou, porém para a maioria ele foi superado. Entretanto, para alguns, os sentimentos de insegurança persistiram, havendo relato de diminuição do rendimento escolar (MORAES; MANZINI, 2006).

Rev. Fac. Educ. (Univ. do Estado de Mato Grosso), Vol. 28, Ano 15, № 2 p. 99-112, jul./dez. 2017 (Epub Ahead of Print 8. out., 2017) 
Os estudantes também avaliaram os aspectos relativos à sua experiência com o PBL. Entre os aspectos destacados, está a valorização da compreensão da pessoa e não da doença, que requer articulação e integração das dimensões biopsicossociais e, desse modo, a mudança de concepção de saúde de uma visão fortemente biologista, para uma visão mais ampla sobre a pessoa e a sua saúde, e as relações estabelecidas com o seu contexto de vida. Ainda estava presente a valorização da motivação interna para estudar os problemas em PBL, partindo tanto da curiosidade e interesse dos estudantes quanto da mediação do tutor (MORAES; MANZINI, 2006).

Em relação ao papel do tutor, os discentes tinham a expectativa de poder contar com tutores que não os deixassem sair com conceitos errados das tutorias. Alguns estudantes ainda sugeriram que os docentes-tutores deveriam saber o conteúdo discutido na tutoria para os questionar. Assim os tutores que não sinalizavam os erros propiciavam mais insegurança aos estudantes do primeiro semestre, que ainda não confiavam em sua capacidade de auto-aprendizagem com a facilitação do tutor (MORAES; MANZINI, 2006).

$\mathrm{Na}$ avaliação dos aspectos negativos do PBL, os estudantes se concentraram na falta de conteúdos teóricos das ciências básicas, normalmente valorizados nas primeiras séries do curso médico, e explicitaram a dificuldade inicial de aprender a estudar sozinhos esses conteúdos, ou seja, de encontrar recursos para superar suas dificuldades na auto-aprendizagem (MORAES; MANZINI, 2006).

Em um estudo realizado em 2007, com estudantes matriculados no primeiro semestre letivo, cursando a disciplina eletiva Políticas Públicas de Saúde Mental da UFRJ, que utilizava metodologia ativa, revelou que 83,3\% dos estudantes consideravam a metodologia satisfatória, com destaque para os seguintes aspectos: as visitas aos cenários de práticas contribuíram para a formação profissional; a interação dos aspectos teóricos e práticos foram bastante satisfatórios; a contribuição da disciplina para a compreensão do funcionamento do SUS; a avaliação formativa, na medida que oferece possibilidades de ressignificação de experiências e saberes em momentos diferenciados do curso; a metodologia ativa foi considerada adequada para a disciplina (GOMES et al., 2010).

Neste mesmo estudo, em relação ao seu próprio desempenho no curso, $78 \%$ dos estudantes assumem ter participado ativamente nos ambientes de aprendizagem e que isto contribuiu para a aquisição de novos conteúdos sobre a saúde mental e sua rede de assistência. Em outro quesito, 92\% dos estudantes afirmam sentirem-se preparados para estagiar na rede pública de 
saúde mental após o término da disciplina. Podendo-se concluir que, ao contrário das disciplinas eminentemente teóricas, a vivência destes estudantes nos cenários de prática fez toda a diferença no desenvolvimento das competências necessárias para o trabalho na rede, sendo este, um mérito da disciplina.

Os estudantes também responderam questões que demandavam uma autocrítica em relação aos aspectos que indicavam, de certa forma, o grau de empenho no andamento da disciplina. Os resultados obtidos levaram a inferir que existem aspectos a serem melhorados, a depender da continuidade, da persistência e da insistência na adoção dos métodos de ensino que confiram mais autonomia e responsabilidade aos estudantes na construção do seu saber (GOMES et al., 2010).

Ainda neste estudo, os alunos também destacaram dois itens relacionados ao docente: a implicação do docente (entusiasmo) com a disciplina, por $96 \%$ dos estudantes; a possibilidade de repetir a experiência com o mesmo professor, por $82 \%$ dos alunos (GOMES et al., 2010).

Outro estudo realizado pela Faculdade de Medicina de Marília, com estudantes do primeiro semestre de 2014, demonstrouque os depoimentos dos estudantes vislumbravam aspectos importantes: com destaque para as sessões de tutoria como um cenário que consolida os conhecimentos e reconhecem a metodologia de ensino PBL como uma estratégia que facilita a aprendizagem bem como a importância de saber buscar o conhecimento em sua prática profissional; valorização do trabalho em grupo, favorecendo atitudes e habilidades que o convívio em grupo proporciona, preparando-os para as exigências da vida profissional; e valorização da integração teoria e prática, levando o conhecimento teórico obtido nas tutorias para subsidiar a prática (FRANCISCO et al., 2015).

Um problema apontado pelos estudantes neste estudo, foi o fato de não conseguirem identificar os recortes de conhecimentos delimitados nos problemas, dificultando conhecer o que deveriam estudar, dirigindo assim, seus estudos, suas buscas e discussões em tutorias para assuntos destacados em algum ponto de referência e para as conferências, uma vez que foram informados que os conteúdos das mesmas seriam cobrados nas avaliações (FRANCISCO et al., 2015).

Um estudo descritivo e quantitativo realizado pela Faculdade de Medicina de Montes Claros- Unimontes, no ano de 2012, concluiu que diversos aspectos deveriam ser melhorados e aperfeiçoados para que a metodologia ativa cumprisse sua missão em formar médicos questionadores, políticos e agentes de mudanças na sociedade atual.

Rev. Fac. Educ. (Univ. do Estado de Mato Grosso), Vol. 28, Ano 15, № 2 p. 99-112, jul./dez. 2017 (Epub Ahead of Print 8. out., 2017) 
Uma das questões levantadas foi em relação ao estímulo do discente em seminários, onde apenas $25 \%$ deles disseram se sentir estimulados a participar e realizar seminários. Outra questão foi relacionada ao desenvolvimento de projetos de pesquisa e extensão, cujos resultados indicam pouco envolvimento dos estudantes neste aspecto, onde somente a metade dos discentes disseram ser algumas vezes estimulados a realizá-los e a outra metade referiu ser dificilmente ou nunca estimulados. Estes dados demonstram a importância de uma discussão mais densa e compartilhada entre profissionais que atuam junto ao estudante (MOURÃO et al., 2012)

Um relato de experiência de estudantes de graduação em Medicina da Universidade Vila Velha na disciplina de Interação Comunitária, realizado em 2012, chama a atenção, que foi a satisfação global dos estudantes com a inserção precoce em estágios rurais que são bem propícios à preceptoria de Médicos de Saúde da Família e Comunidade atuantes no Brasil. Também mostrou bons resultados na satisfação pessoal dos alunos, e consequentemente, no seu desempenho acadêmico por meio do contato com a prática profissional de qualidade desde os primeiros anos do curso de medicina e, de forma mais intensa, na inserção precoce em comunidades rurais. Essa relação positiva ocorreu não somente nas atividades de interação comunitária, mas repercutiu em todas as demais disciplinas (DALLA; MOURA; BERGAMASCHI, 2015).

Para finalizar,é válido citar um estudo realizado em 2009, pelo Centro Universitário da Serra dos Órgãos, com estudantes do quinto período de Medicina, que demonstra que a transformação da metodologia ativa de ensinoaprendizagem é um ato contínuo. Assim, os resultados apontam para uma boa aceitação da metodologia ativa, a qual foi definida pelos alunos como estimulante e integradora da teoria/prática no ensino médico (COSTA et al., 2011).

\section{Considerações finais}

Diante do entendimento da metodologia ativa de ensino- aprendizagem e do PBL, assim como a avaliação do impacto do método na formação profissional e a visão dos discentes sobre o assunto, pode-se refletir algumas questões importantes. Os discentes que cursam o primeiro semestre apresentaram dentre os pontos negativos a insegurança que sentem ao delimitar o conteúdo que deverão estudar após as sessões tutoriais, bem como a falta de conteúdo das ciências básicas, e a dificuldade de estudarem sozinhos.

Para minimizar a insegurança dos discentes o professor-tutor deve 
nortear os estudos não deixando que fiquem inseguros com o conteúdo que deverá ser abordado. O professor-tutor também deve informar que o conteúdo tanto das áreas básicas quanto clínicas serão abordados ao longo da graduação.

Em relação aos pontos positivos relatados pelos discentes, a grande maioria identifica que as metodologias ativas, como o PBL, proporcionam a valorização do trabalho em grupo, que os prepara para a vida profissional, além de permitir o contato com a comunidade, através de visitas aos cenários de práticas, fortalecendo os conhecimentos adquiridos na teoria.

Assim, pode ser demonstrada a importância da transformação das práticas hegemônicas e tradicionais de ensino no campo da saúde, em métodos centrados nos alunos e na sua busca pela autonomia própria, como as metodologias ativas, provocando a construção de novos objetos do conhecimento e interlocução dos saberes, por meio da estruturação curricular orientada pela integração educação- trabalho.

A aproximação dos estudantes ao campo da saúde pública, problematizando situações experimentadas no SUS, transforma em certezas algumas das apostas iniciais, que contribuem para o desenvolvimento de atividades plurais, significativas e imprescindíveis para a formação do profissional médico.

Outro aspecto considerado importante é que a aprendizagem deve ser contínua, pois a escola não consegue possibilitar o aprendizado de todos os conhecimentos construídos. É importante, então, que o estudante aprenda a aprender, a raciocinar criticamente, a identificar os erros e superá-los. Aprenda também a valorizar a comunicação com as pessoas, a ser responsável, a valorizar os contextos da vida das pessoas para poder exercer a medicina. Este resultado é muito facilitado pela aproximação da teoria com a prática profissional desde o primeiro período do curso.

Conclui-se também que, no Brasil, alguns aspectos devem ser reforçados em busca de melhores resultados. Cabe aqui ressaltar o papel do docente na metodologia ativa. Este deve ajudar a encontrar soluções para as dificuldades de adaptação ao método; deve ser, enquanto profissional de educação e saúde, mediadores de seus conhecimentos, facilitadores de estratégias que possam ajudá-lo a retomar seu equilíbrio cognitivo e emocional, para enfrentar novos desequilíbrios.

Vale ressaltar que estudantes do primeiro período do curso médico, ainda vivem o conflito de indefinição do seu papel, em serem passivos ou ativos na construção de seus conhecimentos, independentes ou dependentes - comum conflito vivenciado nesta fase do desenvolvimento. Caberia aos docentes acompanhá-los neste período de busca de identidade adulta, de

Rev. Fac. Educ. (Univ. do Estado de Mato Grosso), Vol. 28, Ano 15, № 2 p. 99-112, jul./dez. 2017 (Epub Ahead of Print 8. out., 2017) 
independência, autonomia e aprendizagem.

A construção coletiva e permanente do currículo com metodologias ativas pode propiciar mudanças nas concepções de ensino- aprendizagem. 0 fortalecimento da educação continuada junto aos docentes e profissionais de saúde é um pilar fundamental para apoiar esta transformação, visando sempre a formação de um profissional generalista, ético, crítico, reflexivo e sempre em busca de aprender para exercer o seu fazer, o seu ser, ao lado de outras pessoas.

\section{Referências}

ALMEIDA, M. J. A educação médica e as atuais propostas de mudança: alguns antecedentes históricos. Revista Brasileira de Educação Médica, v. 25, n. 2, 2001, p. 42-52.

BRASIL. Conselho Nacional de Educação, Câmara de Educação Superior. Resolução CNE/ CES no 4 de 7 de novembro de 2001. Institui Diretrizes Curriculares Nacionais do Curso de Graduação em Medicina. Diário Oficial da União. Brasília, 9 de novembro de 2001; Seção 1, p. 38.

BRASIL. Lei no 9.394 de 20 de dezembro de 1996. Estabelece as Diretrizes de Educação Nacional. Diário Oficial da União, Brasília, 23 de dezembro de 1996.

BRASIL. Ministério da Saúde. Ministério da Educação. Programa nacional de reorientação da formação profissional em Saúde (Pró- saúde): objetivos, implementação e desenvolvimento potencial. Brasília: Ministério da Saúde/ Ministério da Educação, 2007.

BRASIL. Ministério da Saúde/ Ministério da Educação. Organização Panamericana de Saúde. PROMED-Programa de incentivo a mudanças curriculares nos cursos de Medicina. Brasília: Secretaria de Políticas de Saúde, 2002.

CAPRA, F. O ponto da mutação: a ciência, a sociedade e a cultura emergente. São Paulo: Cultrix, 2006.

COLL, C. Psicologia e currículo: uma aproximação psicopedagógica a elaboração do currículo escolar. São Paulo: Ática, 2000.

COSTA, J. R. B., et al. Metodologias ativas de ensino- aprendizagem: a visão de estudantes de Medicina sobre a aprendizagem baseada em problemas. Revista Brasileira de Educação

Médica, v. 35, n. 1, 2011, p. 13-19. 
DALLA, M. D. B.; MOURA, G. A. G. M.; BERGAMASCHI, M. S. Metodologias ativas: um relato de experiência de estudantes de graduação em medicina da Universidade Vila Velha na disciplina Interação Comunitária. Revista Brasileira de Medicina da Família e Comunidade, v. 10, n. 34, 2015, p. 1-6.

FRANCISCO, A. M. et al. Percepção de estudantes e docentes sobre uma unidade educacional em curso de Medicina com metodologia ativa. Investigação Qualitativa em Educação, v. 2, 2015, p. 214-219.

GOMES, A. P.; REGO, S. Transformação da Educação Médica: é possível formar um novo médico a partir de mudanças no método de ensino-aprendizagem? Revista Brasileira de Educação médica, v. 35, n. 4, 2011, p. 557-566.

GOMES, M. P. C. et al. O uso de metodologias ativas no ensino de graduação nas ciências sociais e da saúde-avaliação dos estudantes. Ciência e Saúde, v. 16, n. 1, 2010, p. 181-198.

KOMATSU, R. S.; ZANOLLI, M. B.; LIMA, V. V. Aprendizagem baseada em problemas. São Paulo: Savier, 1998.

MARSIGLIA, R. G. Redação ensino/serviços: dez anos de integração docenteassistencial no Brasil. São Paulo: Hucitec, 1995.

MITRE, S. M. Ativando processos de uma mudança em uma aldeia de Belo Horizonte: uma experiência com metodologia ativa de ensino-aprendizagem. 2006. Trabalho de Conclusão de Curso (Especialização) Especialização em Ativação de Processos de Mudança na Formação Superior de Profissionais de Saúde, Fundação Oswaldo Cruz, 2006.

MITRE, S. M. et al. Metodologias ativas de ensino- aprendizagem na formação profissional em saúde: debates atuais. Ciência \& Saúde Coletiva, v. 13, supl. 2, 2008, p. 2133-2144.

MORAES, M. A. A.; MANZINI, E. J. Concepções sobre a aprendizagem baseada em problemas: um estudo de caso na Famema. Revista Brasileira de Educação Médica, v. 30, n. 3, 2006, p. 125-135.

MOURÃO, M. G. M., et al. Metodologias ativas na graduação médica. Motricidade, v. 8 , n. S2, 2012, p. 875-881.

NTYONGA-PONO, M. P. Problem- based learnig at the Faculty of Medicine of the Université de Montréal: a situated cognition perspective. Medical Education, v. 11, n. 21, 2006, p. 1-13.

PAGLIOSA, F.L.; ROS, M.A. O Relatório Flexner: para o Bem e Para o Mal. Revis-

Rev. Fac. Educ. (Univ. do Estado de Mato Grosso), Vol. 28, Ano 15, № 2 p. 99-112, jul./dez. 2017 (Epub Ahead of Print 8. out., 2017) 
ta Brasileira de Educação Médica, v. 32, n.4, 2008, p. 492-499.

WOOD, D. F. Problem- based learning. British Medical Journal, v. 326, n. 8, 2003, p. 328-330.

Data de recebimento: 08.02.2017

Data de aceite: 19.06.2017 